\title{
Pluralidade de abordagens analíticas da primeira das Três Peças para Piano op. 11, de Arnold Schoenberg
}

Carlos Almada

(Universidade Federal do Rio de Janeiro)

\begin{abstract}
Resumo: O foco do presente artigo é a multiplicidade de perspectivas levadas em conta em uma análise musical, a partir de um caso especialmente selecionado: a primeira das Três Peças para Piano op. 11, de Arnold Schoenberg. A razão dessa escolha se apóia na existência de um rico painel de abordagens analíticas em relação à referida peça, não apenas em número, mas também considerando enfoques, estratégias e resultados. A metodologia deste estudo consiste na descrição de seis dessas análises, realizadas por autores de reconhecido gabarito, compreendendo um período de quatro décadas (Perle, 1962; Wittlich, 1974; Ogdon, 1981; Haimo, 1996 e Lerdahl, 2001), e a apresentação de seus principais pontos de contato e divergências, a partir do estabelecimento de alguns parâmetros comparativos.
\end{abstract}

Palavras-chave - Schoenberg; Três Peças para Piano op.11/1; análise musical.

PLURARITY OF ANALYTICAL APPROACHES: THE FIRST OF THE THREE PIANO PIECES OP.11, BY ARNOLD SCHOENBERG

Abstract: The focus of the present article is the multiplicity of perspectives taken into account for musical analysis, which was here applied to a special case: the first of the Three Piano Pieces op.11, by Arnold Schoenberg. The choice of this particular example was based on the existence of a rich panel of analytical approaches of this piece, not only in number, but also regarding focus, strategy and results. The methodology of this study consists on the description of six of those approaches, elaborated by well-known authors over a period of four decades (Perle, 1962; Wittlich, 1974; Ogdon, 1981; Haimo, 1996 e Lerdahl, 2001), and in the presentation of their main mutual convergences and divergences, under the light of some established comparative parameters.

Keywords - Schoenberg; Three Piano Pieces op.11/1, musical analysis. 


\section{Introdução}

A primeira das Três Peças para Piano op.11 (a partir deste ponto, identificada como op.11/1), composta por Arnold Schoenberg em 1909, é por muitos considerada uma das obras musicais mais importantes já escritas. Sua relevância deve-se, antes de tudo, ao fato de o ciclo do qual faz parte ser reputado como a primeira experiência de composição integralmente desvinculada de um centro tonal de referência. Apesar de sua relativa brevidade e de uma escrita idiomática não exatamente virtuosística (considerando peças similares contemporâneas), o op.11/1 atrai atenção não apenas por sua primazia histórica, mas também pela condição especial que apresenta: uma linguagem harmônica inteiramente nova sobre uma estrutura formal-temática consideravelmente tradicional. É provável que essa conjunção de atributos seja a principal razão pela qual tantos analistas tenham se dedicado a estudar a referida peça. Porém, o que torna o exame dessas análises especialmente marcante não é apenas sua quantidade, mas sim, principalmente, a diversidade (e mesmo discrepância) de enfoques e de resultados.

Este estudo pretende apresentar e confrontar alguns desses trabalhos analíticos, buscando não só destacar seus pontos em comum e divergências, como propor uma reflexão a respeito das potencialidades de uma análise musical, principalmente, em relação à existência, para uma mesma situação-problema, de soluções distintas - e até mesmo antagônicas - e ainda assim plausíveis, em seus próprios termos.

\section{Descrição da metodologia}

Todo o estudo está baseado na descrição sucinta de seis análises selecionadas, realizadas pelos seguintes autores: George Perle (1962), Gary Wittlich (1974), Allen Forte (1981), Will Ogdon (1981), Ethan Haimo (1996) e Fred Lerdhal (2001). 
De modo a estabelecer parâmetros comparativos entre as análises, em cada uma delas serão destacados principalmente os seguintes pontos: (1) enfoque analítico adotado em relação à estrutura formal e à organização melódicoharmônica; (2) métodos e terminologia empregados. Além disso, julgo também importante comparar as maneiras particulares com que cada analista age a partir de seu conjunto referencial. Para isso, na evidente impossibilidade de comentar as seis análises em sua integridade, foram escolhidos dois trechos específicos da peça (c.1-3 e c.12-13), que se tornam assim uma espécie de variáveis de controle. A escolha foi pautada pela importância estrutural de ambos os trechos (reconhecida pelos seis analistas), o que os torna representativos e, portanto, de grande utilidade para a comparação das diferentes abordagens.

As eventuais semelhanças e desacordos entre as linhas analíticas serão destacadas à medida que forem surgindo (as descrições e comentários das análises seguem a ordem cronológica de suas publicações).

\section{Apresentação das análises selecionadas}

\section{Perle (1962)}

A análise do op.11/1 de George Perle encontra-se em seu bem conhecido livro Serial composition and atonality (Perle, 1962), um dos primeiros a abordar de uma maneira sistemática a análise da música não-tonal. Abrangendo um grande número de peças de diversos compositores (principalmente Schoenberg, Berg, Webern, Stravinsky e Milton Babbitt, além de outros), o texto é dividido em duas partes essenciais: atonalismo e serialismo (não apenas o dodecafônico, embora este tenha o maior destaque).

O exame do op.11/1 ocupa uma breve extensão do texto (p. 10-16) e privilegia o tratamento melódico-harmônico, dedicando apenas alguns comentários indiretos (e um tanto elípticos) sobre a forma do op.11/1, como por exemplo é o caso da identificação daquele que é pelo autor denominado tema $B$ (c. 4-8). ${ }^{1}$ Menções lacônicas sobre a existência de uma seção de desenvolvimento

\footnotetext{
${ }^{1} \mathrm{O}$ que leva à dedução de que o trecho entre os c. 1 e 3 corresponderia a um tema $\mathrm{A}$.
} 
(iniciada no c. 25) ${ }^{2}$ e de uma reexposição (c. 53) sugerem (mais do que confirmam) a interpretação de Perle para a estrutura da peça, como ajustada aos moldes de um movimento em forma-sonata.

Em relação ao material melódico-harmônico empregado, Perle destaca como elemento gerador principal uma célula básica [basic cell] formada por três classes de alturas que se inter-relacionam por intervalos de segunda menor, terça menor e terça maior. ${ }^{4}$ Tal célula surge no trecho inicial (c. 1-3), e a partir dela são extraídos - como aponta o autor - todos os elementos que compõem o enunciado do tema principal: tanto a linha melódica quanto seu acompanhamento harmônico (ver ex. 1).

Exemplo 1 - emprego da célula básica nos c. 1-3 do op.11/1, segundo Perle

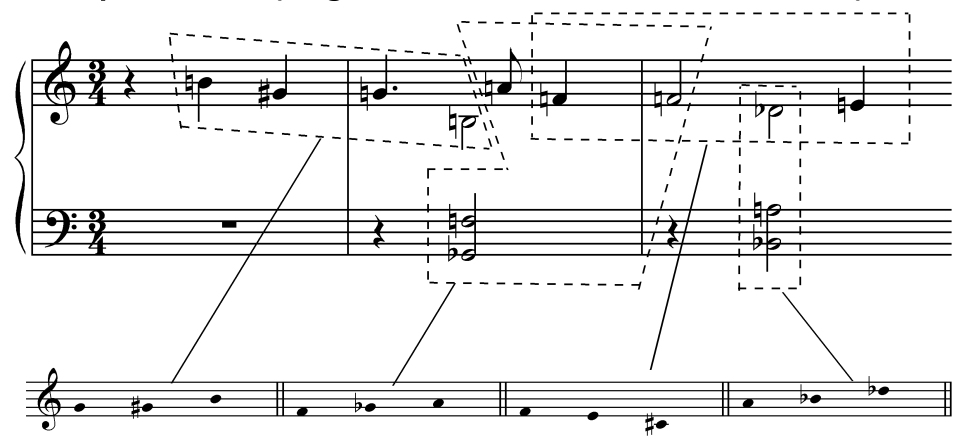

Deixando de lado as diversas manipulações e permutações da célula básica mencionadas por Perle em sua análise do op.11/1, o segundo trecho de exame (c.12-13) representa para o analista a entrada de "um outro elemento temático" (Perle, 1962, p. 12), que é ladeado por manifestações da célula básica (ver ex. 2a). O conjunto que assim se forma é retomado nas mesmas alturas, desta vez verticalizado, como o acorde final da peça (ex. 2b).

\footnotetext{
2 Perle (1962, p. 15).

${ }^{3}$ Perle (1962, p. 15).

${ }^{4}$ Perle não adota nenhuma das duas terminologias que são atualmente empregadas para identificar conjuntos dentro da Teoria dos Conjuntos [Pitch-Set Theory], preferindo indicar em seus exemplos as alturas que as formam. Para uma descrição detalhada dos dois métodos acima citados de identificação das formas primárias [prime forms] dos conjuntos, ver Straus (1990, p. 41-3).
} 
Exemplo 2 - introdução de nova célula (c. 12-13 / 64), segundo Perle

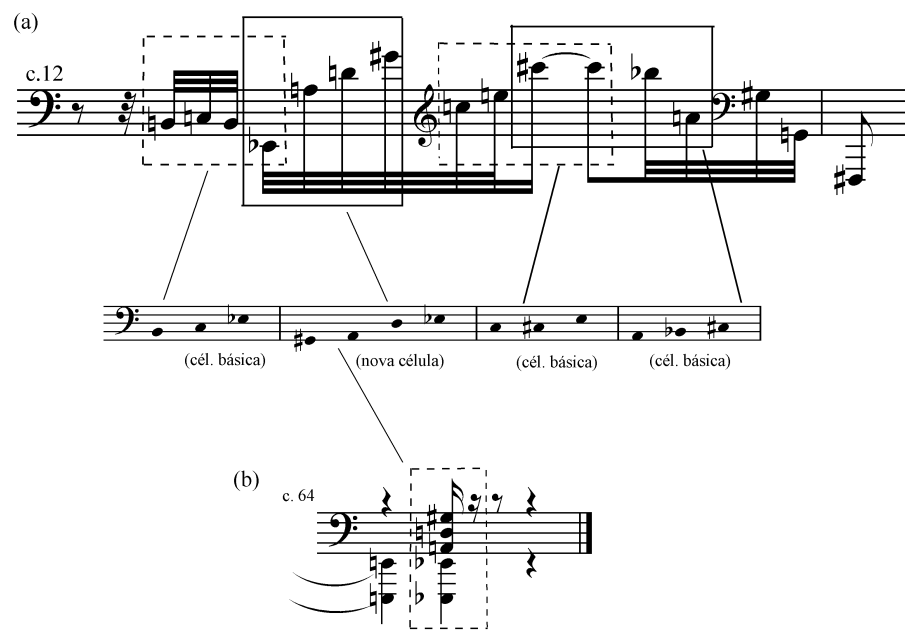

\section{Wittlich (1974)}

A análise deste autor, publicada como artigo do periódico Perspectives of New Music, é bem mais detalhada quanto à organização melódico-harmônica. Em sua introdução, Wittlich comenta a ausência de abordagens mais aprofundadas em relação ao op.11/1, ao mesmo tempo em que critica as interpretações que se apóiam numa estruturação unicamente tricordal para a peça (como é o caso da análise de Perle). Segundo o analista, o principal propósito de seu estudo é demonstrar "o papel organizador exercido por conjuntos de várias extensões, principalmente, hexacordes" (Wittlich, 1974, p. 41).

Formalmente, o autor divide o op.11/1 em cinco seções, que são estreitamente associadas à estrutura melódico-harmônica. São as seguintes: seção I (c. 1-11); seção II (c. 12-18); seção III (c. 19-33); seção IV (c. 34-52) e seção V (c. 53-64). Ainda que não afirme abertamente ser a peça estruturada como formasonata, Wittlich, comentando seu seccionamento, parece adotar de maneira implícita tal interpretação (pelo menos, num nível mais básico): o analista considera o conjunto das seções I e II a exposição do op.11/1, as seções III e IV formando o desenvolvimento e a seção $V$ a reexposição.

É na estrutura dos conjuntos de alturas envolvidos que se encontra o cerne do estudo de Wittllich. Ele as subdivide de acordo com o número de 
componentes (tricordes, tetracordes e hexacordes), dedicando aos grupos por ele denominados "tetracordes e hexacordes primários" [primary tetrachords and hexacordes] uma identificação especial, em ordem alfabética. O quadro 1 reproduz o esquema proposto pelo analista dos sets mais proeminentes do op. 11/1 (Wittlich, 1974, p. 43).

Quadro 1 - conjuntos mais proeminentes do op.11/1, segundo Wittlich

\begin{tabular}{|c|c|c|c|c|}
\hline $\begin{array}{c}\mathrm{N}^{\circ} \text { de } \\
\text { componentes }\end{array}$ & $\begin{array}{l}\text { Comp. da primeira } \\
\text { aparição importante }\end{array}$ & Conjunto & $\begin{array}{l}\text { Identificação } \\
\text { alfabética }\end{array}$ & Vetor intervalar ${ }^{5}$ \\
\hline \multirow[t]{6}{*}{ 年 } & $1-2$ & $\left(\begin{array}{lll}0 & 1 & 4\end{array}\right)$ & & 101100 \\
\hline & 2 & $\left(\begin{array}{lll}0 & 1 & 6\end{array}\right)$ & & 100011 \\
\hline & $2-3$ & $\left(\begin{array}{lll}0 & 1 & 5\end{array}\right)$ & & 100110 \\
\hline & 4 & $\left(\begin{array}{lll}0 & 2 & 6\end{array}\right)$ & & 010101 \\
\hline & 5 & $\left(\begin{array}{lll}0 & 1 & 2\end{array}\right)$ & & 210000 \\
\hline & 20 & $\left(\begin{array}{lll}0 & 4 & 8\end{array}\right)$ & & 000300 \\
\hline \multirow{7}{*}{4} & $1-2$ & $\left(\begin{array}{llll}0 & 1 & 2 & 4\end{array}\right)$ & $\bar{E}$ & 221100 \\
\hline & 2 & $\left(\begin{array}{llll}0 & 1 & 2 & 6\end{array}\right)$ & $\mathrm{F}$ & 210111 \\
\hline & 3 & $\left(\begin{array}{llll}0 & 1 & 4 & 8\end{array}\right)$ & G & 101310 \\
\hline & 12 & $\left(\begin{array}{lllll}0 & 1 & 6 & 7\end{array}\right)$ & & 200022 \\
\hline & 33 & $\left(\begin{array}{llll}0 & 1 & 2 & 5\end{array}\right)$ & & 211110 \\
\hline & 35 & $\left(\begin{array}{llll}0 & 1 & 2 & 3\end{array}\right)$ & & 321000 \\
\hline & $42-43$ & $\left(\begin{array}{llll}0 & 1 & 5 & 6\end{array}\right)$ & & 200121 \\
\hline \multirow{6}{*}{6} & $1-3$ & $\left(\begin{array}{lllllllll} & 1 & 3 & 4 & 5 & 7\end{array}\right)$ & A & \multirow[t]{2}{*}{3333321} \\
\hline & $4-5$ & 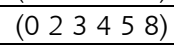 & $A z^{6}$ & \\
\hline & $2-3$ & 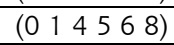 & $\mathrm{B}$ & 322431 \\
\hline & $9-11$ & $(0233468)$ & C & 242412 \\
\hline & $10-11$ & $\left(\begin{array}{llllll}0 & 1 & 2 & 3 & 4 & 7\end{array}\right)$ & $\mathrm{D}$ & \multirow[t]{2}{*}{433221} \\
\hline & $17-18$ & $\left(\begin{array}{llllll}0 & 1 & 2 & 3 & 5 & 6\end{array}\right)$ & $\mathrm{Dz}$ & \\
\hline
\end{tabular}

Um segundo esquema (Wittlich, 1974, p. 44) determina as inclusões presentes nas conjuntos nomeados de A a G, permitindo conhecer seus graus de mútua semelhança e distinção $\mathrm{O}$ quadro 2 reproduz o esquema citado.

${ }^{5} \mathrm{O}$ vetor intervalar apresenta a quantidade de entradas de cada uma das seis classes de intervalos existentes em um determinad conjunto.

${ }^{6}$ A letra "Z" indica conjuntos que compartilham o mesmo vetor intervalar, sem serem membros da mesma set class (i.e., não são mutuamente relacionados através das operações de transposição ou inversão). 
Quadro 2 - inclusões dos tetracordes e hexacordes primários do op.11/1. segundo Wittlich

\begin{tabular}{|c|c|c|}
\hline \multicolumn{2}{|c|}{ Conjunto } & Inclusões \\
\hline$E$ & $\left(\begin{array}{llllllllllllll}0 & 1 & 2 & 4\end{array}\right)$ & $\left(\begin{array}{lllllll}0 & 1 & 2\end{array}\right),\left(\begin{array}{llll}0 & 1 & 4\end{array}\right)$ \\
\hline $\mathrm{F}$ & $\left(\begin{array}{llllllllll}0 & 1 & 2 & 6\end{array}\right)$ & $\left(\begin{array}{lll}0 & 1 & 2\end{array}\right),\left(\begin{array}{llll}0 & 1 & 5\end{array}\right),\left(\begin{array}{llll}0 & 1 & 6\end{array}\right),\left(\begin{array}{lll}0 & 2 & 6\end{array}\right)$ \\
\hline $\mathrm{G}$ & $\left(\begin{array}{lllllllll}0 & 1 & 4 & 8\end{array}\right)$ & $\left(\begin{array}{lll}0 & 1 & 4\end{array}\right),\left(\begin{array}{lll}0 & 1 & 5\end{array}\right),\left(\begin{array}{lll}0 & 4 & 8\end{array}\right)$ \\
\hline A & 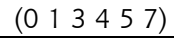 & $\left(\begin{array}{lll}0 & 1 & 2\end{array}\right),\left(\begin{array}{lll}0 & 1 & 4\end{array}\right),\left(\begin{array}{lll}0 & 1 & 5\end{array}\right),\left(\begin{array}{lll}0 & 1 & 6\end{array}\right),\left(\begin{array}{lll}0 & 2 & 6\end{array}\right), E$ \\
\hline $\mathrm{Az}$ & $(023458)$ & 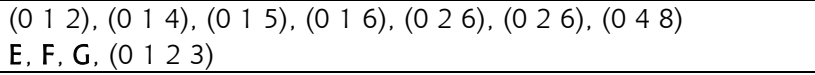 \\
\hline $\mathrm{B}$ & $(0145668)$ & 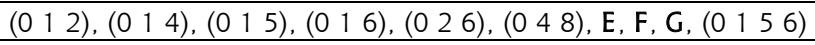 \\
\hline $\mathrm{C}$ & $(0234468)$ & $\begin{array}{l}\left(\begin{array}{lll}0 & 1 & 2\end{array}\right),\left(\begin{array}{lll}0 & 1 & 4\end{array}\right),\left(\begin{array}{lll}0 & 1 & 5\end{array}\right),\left(\begin{array}{lll}0 & 1 & 6\end{array}\right),\left(\begin{array}{lll}0 & 2 & 6\end{array}\right),\left(\begin{array}{lll}0 & 2 & 6\end{array}\right),\left(\begin{array}{lll}0 & 4 & 8\end{array}\right) \\
\left.\text { E, F, G, (0 } \begin{array}{llll}0 & 1 & 2 & 5\end{array}\right)\end{array}$ \\
\hline $\mathrm{D}$ & 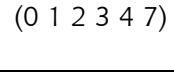 & $\begin{array}{l}\left(\begin{array}{lll}0 & 1 & 2\end{array}\right),\left(\begin{array}{lll}0 & 1 & 4\end{array}\right),\left(\begin{array}{lll}0 & 1 & 5\end{array}\right),\left(\begin{array}{lll}0 & 1 & 6\end{array}\right),\left(\begin{array}{lll}0 & 2 & 6\end{array}\right), E, F, G, \\
\left(\begin{array}{llll}0 & 1 & 2 & 3\end{array}\right),\left(\begin{array}{llll}0 & 1 & 2 & 5\end{array}\right)\end{array}$ \\
\hline Dz & $(0123356)$ & 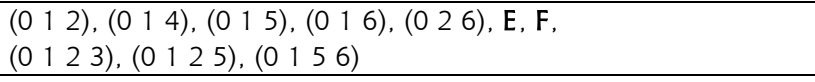 \\
\hline
\end{tabular}

Antes de iniciar o estudo de cada uma das cinco seções, Wittlich, a título de introdução de seu artigo, examina as relações melódico-harmônicas primordiais da peça que, segundo ele, apresentam-se nos seus três compassos iniciais, justificando assim a rede hierárquica de conjuntos apresentada no quadro 1. Wittlich reconhece, como Perle, a relevância construtiva do tricorde $\left(\begin{array}{lll}0 & 1 & 4\end{array}\right),{ }^{7}$ presente como inclusão em quase todos os conjuntos primários (apenas $F$ não o possui), porém sua consideração mais interessante para o trecho de abertura da peça diz respeito à organização hexacordal. Como mostra o ex. 3, o conjunto A é empregado na linha melódica principal, enquanto o conjunto $B$, simetricamente subdividido nos tricordes $\left(\begin{array}{lll}0 & 1 & 6\end{array}\right)$ e $\left(\begin{array}{lll}0 & 1 & 4\end{array}\right),{ }^{8}$ é destinada ao acompanhamento harmônico.

Os hexacordes A e B representam, portanto, segundo Wittlich, os mais importantes conjuntos presentes no op.11/1. O autor destaca o fato de ambos serem "supersets de praticamente todas os conjuntos de menor cardinalidade da peça" (Wittlich, 1974, p.44). ${ }^{9}$

\footnotetext{
${ }^{7}$ Ou seja, a célula básica de Perle, de acordo com sua própria terminologia. Essencialmente, a notação (014) indica a forma primária [prime form] de um tricorde construído a partir de uma altura de referência (o número 0), seguida por duas alturas dela distanciadas, respectivamente, por segunda menor (classe intervalar 1) e terça maior (4).

${ }^{8}$ Para os demais seccionamentos tricordais e tetracordais existentes nos hexacordes $\mathrm{A}$ e $\mathrm{B}$ ver Wiitlich (1974, p. 41-2).

9 Supersets são conjuntos que contém outros menores. Alternativamente, subsets estão contidos em conjuntos maiores.
} 
Exemplo 3 - organização hexacordal do enunciado do op.11/1 (c. 1-3), segundo Wittlich

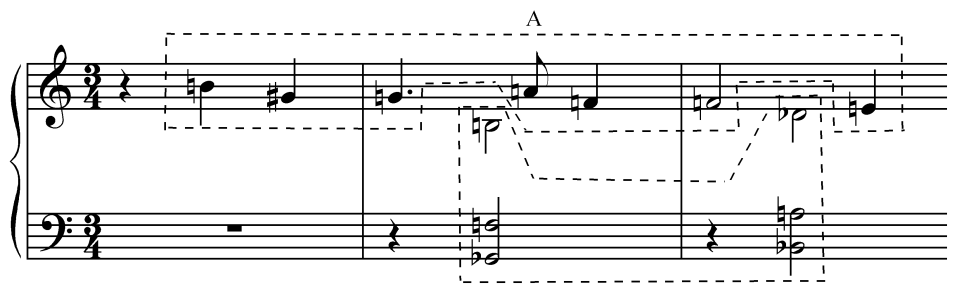

B

No prosseguimento de seu artigo, Wittlich passa a examinar sistematicamente as cinco seções, destacando trechos que considera de maior importância estrutural, que são geralmente analisados sob as três perspectivas de segmentação: tri, tetra e hexacordal.

Dentro da análise da seção I, é pertinente destacar o trecho dos c. 9-11, que retoma o tema principal dentro de outro contexto melódico-harmônico (ver ex. 4). A comparação com o ex. 3 revela, de acordo com Wittlich, uma concepção simétrica por parte de Schoenberg no tratamento do tema principal, empregando nas versões original e recapitulada, respectivamente, os hexacordes A e C para a linha melódica e B e D para a harmonia.

Exemplo 4 - organização hexacordal da retomada do tema principal (c. 9-11), segundo Wittlich

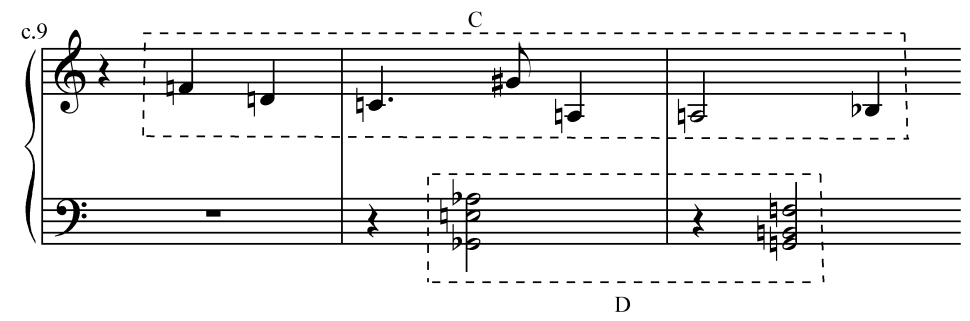

Imediatamente após essa recapitulação, dando início à seção II, surge o segundo trecho de exame comparativo (c. 12-13). A respeito dele, Wittlich apresenta, de início, uma informação bastante interessante: a altura mi, (no segundo tempo do c.12 - ver ex. 5) surge na peça pela primeira vez, completando assim o total cromático. Isso, por si só, concede ao trecho do qual faz parte tal 
nota um posto de relevância construtiva, revelando um destaque planejado pelo compositor. A análise de Wittlich do trecho expõe, além dos tricordes também detectados por Perle, uma organização hexacordal, apoiada na justaposição dos conjuntos B e D (ex. 5), que "apresentam juntas versões lineares de dois sets de acompanhamento [ver ex. 3 e 4] da seção I" (Wittlich, 1974, p. 46). ${ }^{10}$

Exemplo 5- organização hexacordal dos c. 12-13, segundo Wittlich

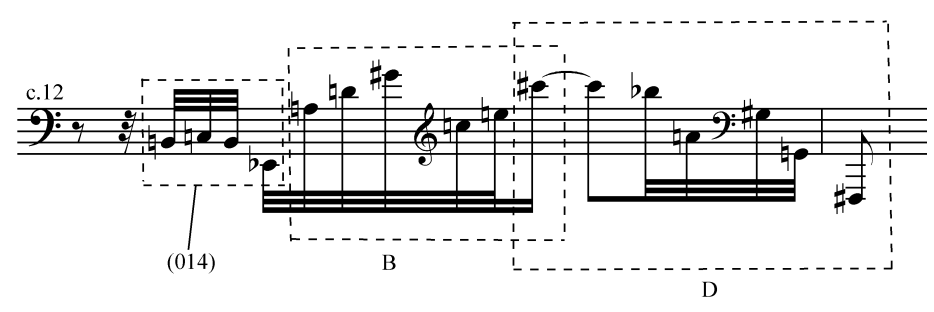

Um outro ponto distintivo do trabalho de Wittlich em relação aos demais analistas é o estabelecimento de relações entre transposições dos hexacordes A e B como fator de articulação formal, num esquema análogo ao das relações entre seções formais e regiões harmônicas presentes na música tonal (mais especificamente, aquelas que governam o arquétipo da forma-sonata). O quadro 3 reproduz o esquema proposto pelo analista (Wittlich, 1974, p. 52).

Talvez os fatos mais notáveis revelados neste esquema sejam sua simetria quase especular e a evidente intenção de Schoenberg de buscar um substituto para as relações entre regiões tonais nessa nova linguagem que se inaugurava. ${ }^{11}$

\footnotetext{
${ }^{10}$ Wittlich critica a ênfase dada por Perle à introdução da nova célula no c.12 (formada pelas alturas mi b, lá, ré e sol\#), como uma espécie de momento de grande renovação dentro da peça. Segundo ele, "é claro que os materiais não são novos (exceto pelo mi b), embora o seja a maneira de apresentação" (Wittlich, 1974, p. 46).

${ }^{11}$ É bastante interessante saber que o compositor tenha mantido essa preocupação mesmo em suas obras seriais, com a utilização de "áreas" e "modulações". Para uma discussão mais aprofundada a respeito desses procedimentos na música dodecafônica de Schoenberg, ver Straus (1990, p. 158-60).
} 
Quadro 3 - relações de alturas das principais manifestações dos hexacordes A e B no op. $11 / 1$

\begin{tabular}{|c|c|c|c|c|c|}
\hline Seção & 1 & II & \multicolumn{2}{|c|}{ IV } & \\
\hline Hexacordes $^{12}$ & $A_{0}$ & $\mathrm{~B}_{3.8}$ & $A_{6.5}$ & $\mathrm{~B}_{8.3}$ & \\
\hline Compasso & 1 & $12-13$ & 34 & $50-51$ & 53,62 \\
\hline
\end{tabular}

\section{Forte (1981) ${ }^{13}$}

O autor inicia seu estudo com uma cronologia da composição do op.11/1 e uma breve revisão da literatura sobre suas análises, "muitas delas buscando de alguma maneira posicionar a peça dentro de uma moldura tonal" (Forte, 1981, p. 129). ${ }^{14} \mathrm{Em}$ seguida, comenta as análises de Perle e de Wittlich, cujas perspectivas, em maior ou menor medida, assemelham-se à sua própria.

A análise de Forte é razoavelmente extensa (41 páginas) e embora como as anteriores - seja focada na organização das dimensões melódica e harmônica, dedica alguns comentários específicos à estrutura formal. O autor afirma que "o contorno geral do movimento é tripartite e assemelha-se ao de uma curta forma-sonata" (Forte, 1981, p. 130), sendo, portanto, o primeiro dos analistas aqui selecionados a adotar explicitamente essa interpretação (embora ela, até este ponto, se sustentasse de uma forma tácita). Como mostra o quadro $4,^{15}$ a segmentação ternária adotada pelo analista é replicada em vários níveis,

12 Os números associados às letras indicam transposições dos sets básicos apresentados originalmente nos c. 1-3 (ou seja, $A_{0}$ e $B_{0}$ ). Duplas de números separados por vírgulas significam duas transposições que são empregadas sucessivamente no trecho em questão.

${ }^{13}$ Análise publicada no Journal of the Arnold Schoenberg Institute (nov./1981), juntamente com a de Will Ogdon (ver a próxima seção deste estudo), ambas agrupadas sob o título: "Op.11, no. 1: Two points of view". No texto introdutório a esses artigos, Leonard Stein, editor do periódico, comenta a oposição radical de pontos de vista de seus autores, que seria resultante, entre outros fatores, das "ambigüidades inerentes nessa composição [o op.11/1]".

14 São as seguintes as referências dos textos citados por Forte: Réti, Rudolph. Formale Erläterungen zu Arnold Schoenbergs Klavierstücke. Der Merkur II, 1910. Leichtentritt, Hugo. Musical Form. Cambridge, 1951. Brinkmann, Reinhold. Arnold Schoenberg: Drei Klavierstücke Op.11: Studien zur frühen Atonaltät bei Schoenberg. Wiesbaden: Franz Steiner, 1969. Samson, Jim. Music in transition: A study of tonal expansion and atonality, 1900-1920. Nova York, 1977.

${ }^{15}$ Adaptação do ex.1 de Forte (Forte, 1981, p. 131) 
sendo sempre representada pelas letras A e B (com minúsculas indicando subseções e colchetes significando subdivisões derivadas das principais), o que resulta numa certa confusão terminológica. Forte afirma que as "decisões analíticas representadas (...) [no esquema formal] são baseadas não apenas nas configurações externas (motivos), mas também levam em conta os componentes harmônicos" (Forte, 1981, p. 130).

Quadro 4 - esquema formal do op.11/1, segundo Forte

\begin{tabular}{|c|c|c|c|}
\hline $1^{\circ}$ nível & $2^{\circ}$ nível & $3^{\circ}$ nível & compasso \\
\hline \multirow[t]{10}{*}{ A. Exposição } & \multirow[t]{3}{*}{ A } & $a$ & $1-3$ \\
\hline & & $b$ & $4-8$ \\
\hline & & $a^{\prime}$ & $9-11$ \\
\hline & \multirow[t]{2}{*}{ B } & Episódio ("material novo") & $12-14$ \\
\hline & & Transição & $15-16$ \\
\hline & A & Retorno de $a^{\prime}$ & $17-18$ \\
\hline & & Retorno de $b$ & $19-24$ \\
\hline & {$[\mathrm{A}]$} & $\begin{array}{l}\text { Episódio canônico, lembrando } b \text {, com } \\
\text { variante de } a\end{array}$ & $25-27$ \\
\hline & [B] & Episódio canônico relacionado aos c. 12-16 & $28-30$ \\
\hline & [A] & Apresentação final de $a$ & $31-33$ \\
\hline \multirow[t]{5}{*}{ B. Desenvolvimento } & \multicolumn{2}{|r|}{$[\mathrm{A}]$} & 34-38 \\
\hline & \multicolumn{2}{|r|}{$[B]$} & $39-41$ \\
\hline & \multirow[t]{3}{*}[\mathrm{A}]{} & & $42-45$ \\
\hline & & & $46-49$ \\
\hline & & & $50-52$ \\
\hline \multirow[t]{3}{*}{ A. Recapitulação } & \multirow[t]{3}{*}{$\bar{A}$} & $a$ & $53-55$ \\
\hline & & $b$ & $56-58$ \\
\hline & & $a^{\prime}$ & $59-64$ \\
\hline
\end{tabular}

Em relação à organização das alturas, o analista apresenta, de início, aquilo que denomina "vocabulário harmônico" do op.11/1: o grupo de conjuntos mais importantes que são utilizadas na composição. Assim como Wittlich, Forte relaciona três tipos de sets, porém, substitui os tricordes por pentacordes. Além disso, agrupa os conjuntos selecionados lado a lado com seus complementos. $\mathrm{O}$ quadro 5 apresenta os sets de Forte acrescentando, a título de comparação, suas correspondências com a classificação proposta por Wittlich.

Como se observa, o "vocabulário" de Forte tem a seguinte composição: (a) seis hexacordes principais, sendo quatro deles (6-Z3, 6-Z10, 6-Z13 e 6-Z19) associados a seus complementos (respectivamente 6-Z36, 6-Z39, 6-Z42 e 6-Z44), 
e dois auto-complementares (6-16 e 6-21):16 (b) seis pentacordes, mais seus complementos (seus respectivos heptacordes, com idênticos números de ordem, não mostrados no quadro 5) e (c) dois tetracordes, com seus respectivos octacordes complementares.(também aqui omitidos).

Quadro 5 - conjuntos principais do op.11/1, segundo Forte

\begin{tabular}{|c|c|c|c|}
\hline Cardinalidade & $\begin{array}{c}\text { Identificação do } \\
\text { conjunto }{ }^{17}\end{array}$ & Vetor intervalar & $\begin{array}{l}\text { Correspondência com a } \\
\text { análise de Wittlich } \\
\text { (ver quadro 1) }\end{array}$ \\
\hline \multirow{10}{*}{6} & $6-Z 3$ & \multirow{2}{*}{433221} & $\mathrm{Dz}$ \\
\hline & 6-Z36 & & $\mathrm{D}$ \\
\hline & $6-Z 10$ & \multirow[t]{2}{*}{333321} & A \\
\hline & $6-739$ & & $\mathrm{Az}$ \\
\hline & $6-Z 13$ & \multirow[t]{2}{*}{324222} & - \\
\hline & $6-Z 42$ & & - \\
\hline & $6-16$ & 322421 & $B$ \\
\hline & $6-Z 19$ & 313431 & - \\
\hline & $6-Z 44$ & & - \\
\hline & $6-21$ & 242412 & $\mathrm{C}$ \\
\hline \multirow{6}{*}{5} & $5-Z 13$ & 221311 & - \\
\hline & $5-Z 17$ & \multirow[t]{2}{*}{212320} & - \\
\hline & $5-Z 37$ & & \\
\hline & $5-Z 18$ & \multirow[t]{2}{*}{212221} & - \\
\hline & $5-Z 38$ & & - \\
\hline & $5-21$ & 202420 & - \\
\hline \multirow[t]{2}{*}{4} & $4-7$ & 201210 & - \\
\hline & 4-19 & 101310 & $G$ \\
\hline
\end{tabular}

O que chama a atenção, na comparação com o esquema de Wittlich são as diferentes quantidades de seus grupos dos hexacordes (nada menos do que quatro novos sets foram detectados por Forte, além daqueles anteriormente listados) e dos tetracordes (Forte não relaciona os proeminentes conjuntos E e F de Wittlich, acrescentando um novo, 4-7).

16 Isto é, hexacordes especiais cujos complementos são conseguidos através de determinadas transposições de seus próprios conteúdos.

17 A terminologia de Forte para os conjuntos é baseada numa relação de todas as possibilidades de combinação de classes de alturas. A identificação consiste na cardinalidade do conjunto (3 para tricorde, 4 para tetracorde etc.), seguida de hífen e um número de ordem. O complemento de um conjunto consiste nos elementos que lhe faltam para a totalização cromática (por exemplo, 8-19 é o complemento de 4-19, e vice-versa). No caso dos hexacordes há duas possibilidades: aqueles auto-complementares (nos quais o complemento é uma versão transposta ou invertida) e duplas de hexacordes em relação $Z$ (ver nota de rodapé $n^{\circ} 8$ ), mutuamente complementares, como os que se apresentam na análise de Forte. Para maiores informações sobre o grupo de relações entre sets mais empregadas na Teoria dos Conjuntos, ver Straus (1990, p. 59-73). 
Em relação aos tricordes, sets de decisiva importância nas análises de Perle e de Wittlich, Forte, justificando o fato de não incluí-los - ao menos oficialmente - em seu "vocabulário", afirma que eles "são ubíquos na música atonal e exercem um papel análogo ao dos motivos em díades na música tonal, enquanto os componentes básicos estruturais são conjuntos maiores - no caso do op.11/1, hexacordes" (Forte, 1981, p.136). Para enfatizar a onipresença dos tetracordes, cita o conjunto inicial da peça (formado pelas alturas sol\#, sol e si, ver ex.1), identificado como - dependendo da terminologia adotada - 3-3 ou (0 14 ), "que é encontrado pelo menos uma vez em cada um dos hexacordes do op.11/1" (Forte, 1981, p. 136).

Forte passa então para uma análise profundamente minuciosa e quase exaustiva da peça, ${ }^{18}$ da qual destaco, para a comparação com os demais estudos, os dois trechos de exame aqui considerados. O ex. 6 reproduz parcialmente e adapta o ex. 5 de Forte (Forte, 1981, p. 139-140), levando em conta apenas os conjuntos principais, segundo o analista.

Exemplo 6 - organização hexacordal do enunciado do op.11/1 (c. 1-3), segundo Forte

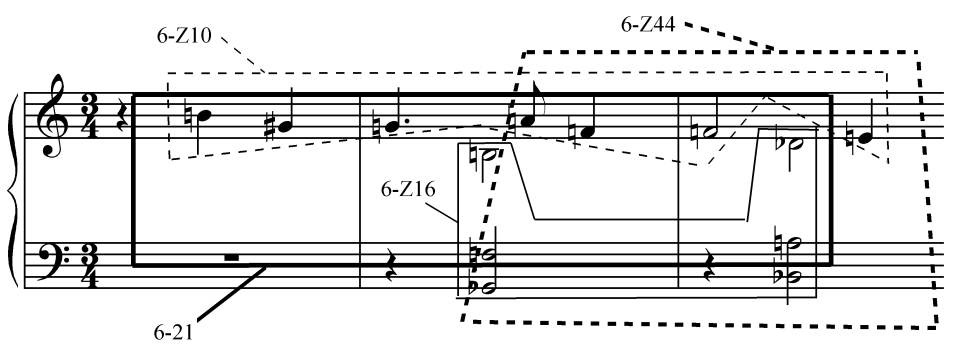

Como se observa, além de manter a disposição previamente estabelecida por Wittlich, com os sets A e B (6-Z10 e 6-Z16 para Forte), responsáveis, respectivamente, por melodia e acompanhamento, Forte propõe mais duas novas segmentações hexacordais (6-21 e 6-Z44) que, além de menos simétricas e lógicas

\footnotetext{
${ }^{18}$ Essa seção da análise, que ocupa a maior parte do artigo de Forte, abrange quase a totalidade territorial do op.11/1 (apenas os compassos 18, 37, 40, 42-44, 47-49 e 56-57 não são examinados). Em cada um dos 16 trechos selecionados, Forte elabora intrincados esquemas gráficos - dois ou três, sendo o primeiro deles sempre dedicado à organização principal - nos quais as diversos conjuntos atuantes são apresentados.
} 
do que as anteriores, apresentam várias alturas sobrepostas. ${ }^{19} \mathrm{O}$ trecho dos c.1213 é mostrado no ex. $7 .^{20}$

Exemplo 7 - organização hexacordal dos c. 12-13, segundo Forte

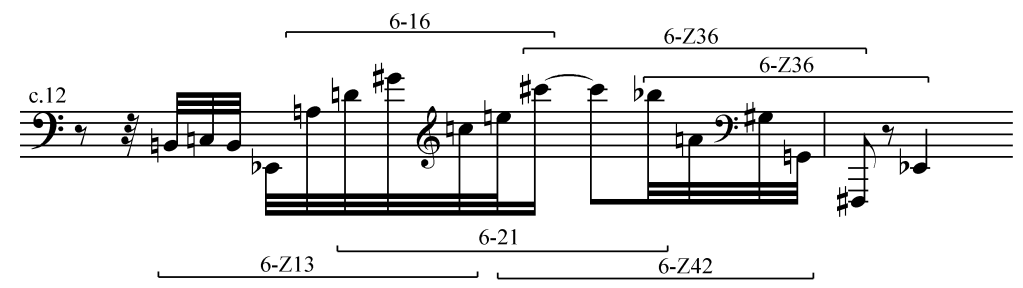

Como se pode observar, há também aqui múltiplas disposições possíveis, ${ }^{21}$ em diferentes superposições. ${ }^{22}$ No entanto, a mais importante delas consiste no biseccionamento do c.12 envolvendo dois hexacordes contíguos 6-Z13 e 6-Z42 (nenhum dos dois se encontra entre os mapeados por Wittlich - ver quadro 5). Forte chama especialmente a atenção para o fato de serem ambos mutuamente complementares (Forte, 1981, p.145).

Em nova concordância com Wittlich, Forte ressalta importância da nota grave mib, como a décima segunda altura a ser apresentada na peça e como o baixo do acorde final. No entanto, atribui a primazia da informação a Webern (Forte, 1981, p. 145)..$^{23}$

\footnotetext{
19 Para não estender demasiadamente o texto deste estudo, nem desviar o foco de suas questões centrais, foram omitidas as demais organizações de sets (pentacordes, tetracordes e mesmo tricordes) apresentadas por Forte neste e no próximo trecho.

${ }^{20}$ Adaptação do ex.7 de Forte (Forte, 1981, p. 144).

${ }^{21}$ Nada menos do que cinco dos seis hexacordes do "vocabulário" estão presentes. Forte critica a interpretação de outros analistas (Perle, entre eles) sobre o fato de o trecho em questão representar harmonicamente uma "mudança radical" dentro da peça. Assim como Wittlich, Forte demonstra (ainda mais consistentemente, aliás) que "em termos do conteúdo hexacordal a passagem é uma referência de todos segmentos mais destacados que a precederam" (Forte, 1981, p. 145).

${ }^{22}$ A combinação de 6-16 e 6-Z36 corresponde à organização hexacordal proposta por Wittlich (comparar com o ex. 5).

${ }^{23}$ C. f. Webern, Anton. O Caminho para a Música Nova. $1^{\text {a }}$ edição. (Carlos Kater, trad.). São Paulo: Novas Metas, 1984, p. 132.
} 
Ogdon (1981)

Adotando um enfoque inteiramente distinto da linha percorrida por Perle, Wittlich e Forte, Will Ogdon busca demonstrar que o op.11/1 possui uma base essencialmente tonal. Por mais bizarra que possa, de início, parecer (em relação ao senso comum, que considera o op.11 schoenberguiano uma obra inteiramente desvinculada de referências tonais), a abordagem de Ogdon possui lógica e consistência, revelando no mínimo uma interessante perspectiva. O analista se apoia principalmente nas notórias intenções de Schoenberg de encontrar um substituto à altura para as forças de organização da tonalidade, questão que tanto o preocupava na época (final da primeira década do séc. XX). Ogdon está convencido que "a tonalidade não apenas existe, mas também funciona estruturalmente no op.11. De fato, existem evidências de que a tonalidade funciona no op.23/1 [do ciclo schoenberguiano intitulado Cinco Peças para Piano], cerca de uma dúzia de anos mais tarde" (Ogdon, 1981, p. 169). ${ }^{24}$

Como principal referência teórica para sua abordagem analítica, Ogdon utiliza os escritos de Schoenberg sobre harmonia, ${ }^{25}$ especificamente os trechos que tratam de procedimentos de maior complexidade, como tonalidade flutuante [scwebend Tonalität]. ${ }^{26} \mathrm{O}$ analista também se apoia na visão schoenberguiana de uma tonalidade expandida, na qual as mais remotas digressões podem ser explicadas à luz de um centro tonal. ${ }^{27}$

Em relação à estrutura formal básica da peça, Ogdon faz poucos comentários, embora, como o que acontece no caso de Perle e de Wittlich, deixe implícita a interpretação de forma-sonata. Num nível mais detalhado, no entanto, o analista introduz uma nova interpretação. Novamente baseado nas próprias

\footnotetext{
${ }^{24}$ Ogdon analisa sumariamente sob o ponto de vista tonal a peça mencionada do op.23 dentro do mesmo artigo (Ogdon, 1981, p.178-81).

${ }^{25}$ Schoenberg (2001) e Schoenberg (2004).

${ }^{26}$ Segundo Norton Dudeque, em trechos onde há a presença tonalidade flutuante existe a "ideia de ambiguidade tonal, isto é, a oscilação entre duas ou mais tonalidades, sem apresentar o sentido de troca de centro tonal, de modulação, mas sim apresentando a possibilidade de relacionamento simultâneo a centros tonais distintos" (Dudeque, 1997. p.134).

${ }^{27}$ Quanto a tal aspecto ver, por exemplo, o conceito schoenberguiano de monotonalidade (Schoenberg, 2004, p. 37) ou as interessantes considerações de Herschkowitz (1974) sobre a existência de uma "tonalidade dodecafônica" na música de Schoenberg.
} 
formulações teóricas de Schoenberg (desta vez relacionadas à forma), Ogdon percebe o tema principal com uma estrutura de período, compreendendo no total 18 compassos. 0 quadro 6 procura sintetizar as considerações do analista:

Quadro 6 - estrutura do tema principal do op.11/1 como período, segundo Ogdon

\begin{tabular}{|c|c|c|c|c|c|}
\hline \multirow{2}{*}{} & \multicolumn{2}{|c|}{ antecedente } & consequente & episódio & $\begin{array}{c}\text { (cont. do } \\
\text { conseq.) }\end{array}$ \\
\cline { 2 - 4 } & $1^{\circ}$ segmento & $2^{\circ}$ segmento & $1^{\circ}$ segmento & & $2^{\circ}$ segmento \\
\hline compassos & $1-3$ & $4-8$ & $9-11$ & $12-17$ & $18-24$ \\
\hline
\end{tabular}

Observa-se uma inusitada interpolação de um episódio entre os dois segmentos que compõem o consequente do tema. Os 24 compassos dessa estrutura completa (período + episódio) formam a seção de exposição da peça, que é seguida pelo desenvolvimento (c.25-52) e pela reexposição (c. 53-64).

Comentando a exposição do op.11/1 sob o ponto de vista da organização harmônica mais básica, Ogdon afirma que

O antecedente completo estabelece a região tônica em Sol [forma tônica]. O consequente repete o modelo, porém na forma dominante. O episódio estabelece a tonalidade competidora de $\mathrm{Mi}$, , mas em modo menor (...). A retomada do consequente começa em Sol, mas sua frase contrastante [c. 2022] resolve na região rival [Mi,], desta vez maior." (Ogdon, 1981, p.170)

Levando isso em conta, é possível, portanto, resumir a estrutura harmônica da peça como uma alternância (e, em alguns trechos, superposição) de dois pólos tonais: Sol (o principal) e Mib, um típico caso de tonalidade flutuante.

A análise harmônica de Ogdon é realizada a partir dessa visão geral. Para isso, o analista estabelece como premissa um tipo de organização hierarquizada das doze alturas em sete categorias (portanto, num diatonicismo centrado em sol), como mostra o quadro $7: 28$

Quadro 7 - classificação das alturas do op.11/1, segundo Ogdon

\begin{tabular}{|l|rrr|rr|rr|rrr|rr|rr|r|}
\hline $\mathrm{C} \#$ & $\mathrm{Ab}$ & $\mathrm{A}$ & $\mathrm{A} \#$ & $\mathrm{Bb}$ & $\mathrm{B}$ & $\mathrm{C}$ & $\mathrm{CH}$ & $\mathrm{Db}$ & $\mathrm{D}$ & $\mathrm{D} \#$ & $\mathrm{~Eb}$ & $\mathrm{E}$ & $\mathrm{F}$ & $\mathrm{F} \#$ & \multicolumn{1}{l|}{ b } \\
\hline$\# 1$ & $\mathrm{~b} 2$ & 2 & $\# 2$ & 3 & +3 & 4 & $\# 4$ & b5 & 5 & $\# 5$ & 6 & +6 & 7 & $\# 7$ & 1 \\
\hline
\end{tabular}

\footnotetext{
${ }^{28}$ Adaptação do esquema apresentado por Ogdon (1981, p. 170).
} 
A análise do enunciado do tema (c.1-3), de acordo com os procedimentos metodológicos de Ogdon é a seguinte (ex. 8): $:^{29}$

Exemplo 8 - análise harmônica do início do antecedente do tema principal do op.11/1 (c.1-3), segundo Ogdon

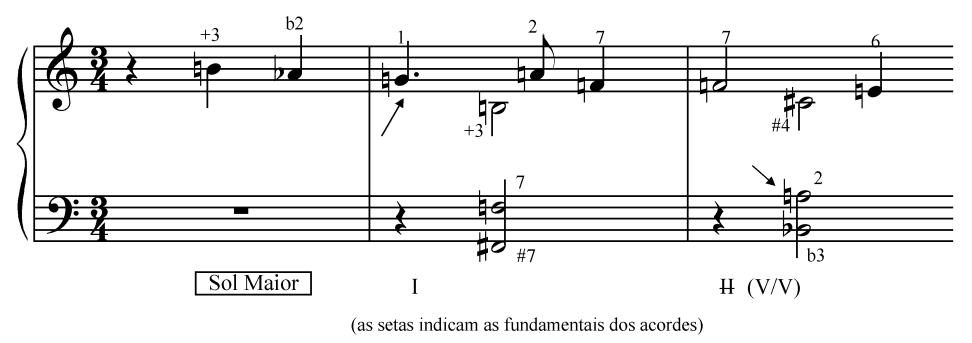

Como se observa, o analista transcreve enarmonicamente algumas notas (p.ex., o láb do c.1 ou o dó\# do c.3), de modo a tornar mais evidentes as tendências melódico-harmônicas e as relações tonais.

O segundo trecho de exame (c.12-13), que corresponde ao início do episódio, exige do analista um outro tipo de abordagem, em virtude da ausência de acompanhamento com acordes (ex. 9). ${ }^{30}$

Exemplo 9 - análise harmônica do início do episódio do op.11/1 (c.12-13), segundo Ogdon

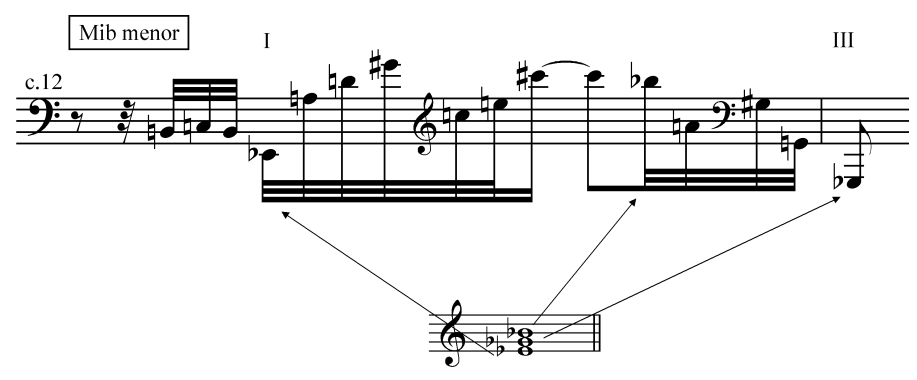

Afirmando que uma progressão harmônica I-III em Mi, menor pode ser inferida (Ogdon, 1981, p. 173), o analista destaca as notas que formam o arpejo

\footnotetext{
${ }^{29} \mathrm{O}$ ex.8 reproduz parcialmente o ex.1 do artigo de Ogdon (Ogdon, 1981, p.171).

${ }^{30} \mathrm{O}$ ex.9 reproduz parcialmente o ex.6 do artigo de Ogdon (Ogdon, 1981, p.173).
} 
da tríade tônica dessa nova região como pontos estruturais importantes da linha, interligados por notas "estranhas". ${ }^{31}$

\section{Haimo (1996)}

O ensaio de Haimo pode ser dividido em duas partes: na primeira delas, que se inicia com uma discussão a respeito da assim chamada "falácia intencional" [intencional fallacy], ${ }^{32}$ adaptada para a esfera da análise musical, o autor critica com uma certa contundência os métodos desenvolvidos por Allen Forte, principalmente quando empregados no exame da obra atonal de Schoenberg. Haimo divide as análises em dois tipos: $\left(1^{\circ}\right)$ as que levam em conta as intenções do compositor e $\left(2^{\circ}\right)$ as que se baseiam apenas nos eventos presentes na partitura e nas interpretações do analista, desconsiderando (ou considerando irrelevantes) o que dita a opinião do compositor. A isso acrescenta um fato bem conhecido da pesquisa musicológica, que é a inexistência de quaisquer referências por parte de Schoenberg - ou de seus alunos mais famosos, Berg e Webern - sobre uma organização melódico-harmônica baseada em conjuntos de classes de alturas (sejam eles provenientes de esquetes, rascunhos, cartas ou mesmo textos teóricos) para sua música do período atonal, em contraste com o que acontece em relação à técnica dodecafônica, cuja documentação sobre formulações teóricas, cálculos e anotações em geral existe em grande quantidade na obra composicional e/ou textual de próprio punho desses compositores. Segundo a crítica de Haimo, o método de Forte (principalmente representado pela análise do op.11/1), além de muitas vezes arbitrário e tendencioso na questão da segmentação dos sets, que considera o aspecto mais problemático de suas análises, ${ }^{33}$ falha pela incoerência,

${ }^{31} \mathrm{O}$ autor não procura explicar tais notas sob a perspectiva do novo centro tonal nem justifica a escolha dos pontos estruturais (principalmente o sib), o que parece ser um ponto falho de sua tese.

32 De um artigo de mesmo título, proveniente do campo da crítica literária, publicado originalmente em 1946 por William Winsatt e Monroe Beardsley (apud Haimo, 1996, p. 176).

${ }^{33}$ Referindo-se especialmente à análise do op.11/1 (Forte, 1981). Haimo cita, entre outros, o caso das várias segmentações hexacordais possíveis para o trecho dos c. 1-3 (ver o ex.6). Afirma ainda que, de acordo com os critérios de Forte, "poder-se-ia, na verdade, propor literalmente dúzias de possíveis segmentações apenas para a primeira frase" (Haimo, 1996. p. 184), o que estende, a seguir, a toda a peça. Em outro momento, comentando abordagens divergentes em trechos do op.11/1 que apresentam semelhanças motívicas e 
pois, embora na maior parte do tempo considere as intenções do compositor irrelevantes para sua análise (o que a classificaria, de acordo com Haimo, como pertencente ao $2^{\circ}$ tipo), em diversos momentos procura convenientemente fundamentar suas escolhas em depoimentos e procedimentos schoenberguianos presumidamente recorrentes (como acontece em análises do $1^{\circ}$ tipo)..$^{34}$

A despeito disso, Haimo não considera a Teoria dos Conjuntos de todo inadequada para análise da música atonal schoenberguiana, desde que sempre "possa satisfazer o critério da testibilidade [criterion of testibility]" (Haimo, 1996, p. 190). Segundo sua concepção, o principal problema do método é que quando aplicado rigorosamente não deixa perceber a fronteira entre o essencial e o trivial. Seguindo seu raciocínio, mesmo a escolha unicamente pautada numa segmentação primária (p.ex., aquela proposta por Wittlich para os c. 1-3 e 9-11 ver exs. 3 e 4), se aplicada a toda extensão da peça, resultaria numa "distribuição dos sets próxima do aleatório" (Haimo, 1996, p.191).

A segunda parte do texto de Haimo se destina à sua própria proposta de análise do op.11/1. Seu enfoque analítico é direcionado unicamente às transformações de maior alcance sofridas por três motivos básicos que surgem nos compassos iniciais da peça, deixando de lado, ao contrário dos analistas anteriores, quaisquer considerações a respeito da estrutura formal e da organização harmônica. Em outros termos, sua análise fundamenta-se no conjunto de processos construtivos denominado variação progressiva [developing variation], técnica notoriamente reconhecida como de uso intenso por parte de Schoenberg em todas as suas fases composicionais. Haimo argumenta que é justamente no exame do gradual desenrolar e no inter-relacionamento de tais ideias motívicas essenciais que se encontra a chave das escolhas de Schoenberg dentro do op.11/1. Haimo deixa claro que suas conjecturas, embora também não corroboradas

texturais entre si, conclui que, da análise de Forte se depreende que "o ritmo é irrelevante como critério de segmentação em análises de conjuntos de classes de altura, já que segmentações completamente diferentes são feitas em passagens de idêntico ritmo" (Haimo, 1996, p. 187).

${ }^{34}$ Haimo (1996, p. 188-190). 
diretamente por anotações nos esquetes e rascunhos do op. 11 , $^{35}$ apoiam-se na própria prática geral do compositor - em seu conhecido modus operandis. Diz o analista: "ainda que minha análise aconteça nos termos do $2^{\circ}$ tipo (...), as premissas fundamentais que a motivaram são baseadas em assunções do $1^{\circ}$ tipo que Schoenberg, de fato, compôs nos termos da variação progressiva" (Haimo, 1996, p. 198).

Os três motivos de Haimo, cada qual formado por um conjunto de três notas (e dois intervalos contíguos), são identificados pelas letras $a, b$ e $c$, com suas respectivas variantes, numeradas com algarismos arábicos. 0 ex. $10^{36}$ apresenta as primeiras versões desses motivos, resultantes de sucessivas mutações de suas abstrações (indicadas abaixo da partitura em notas sem hastes).

Exemplo 10 - motivos a, b e c e variantes no enunciado do op.11/1 (c.1-5), segundo Haimo
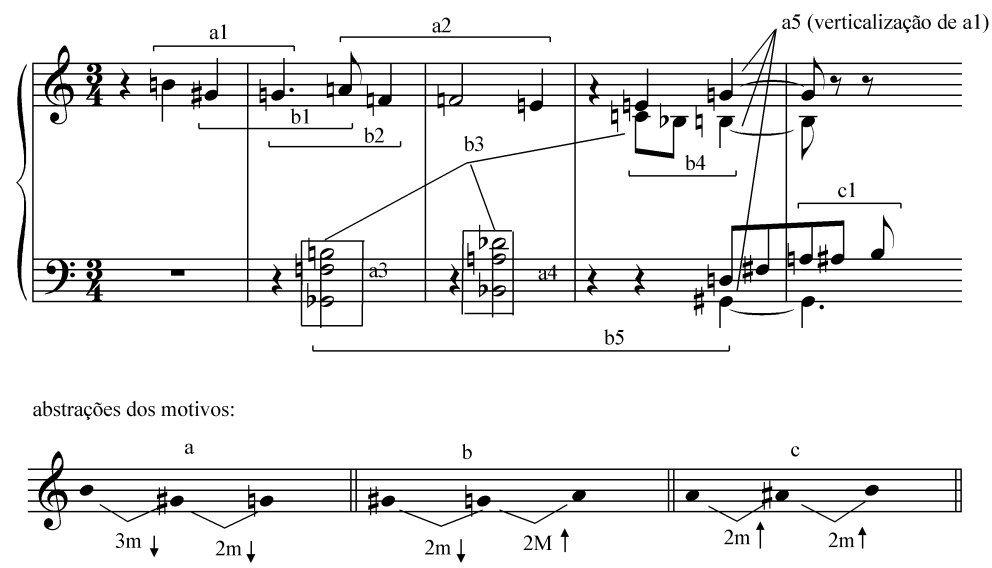

De acordo com Haimo,

no op.11/1 um número limitado de motivos fundamentais provê a fonte de material para o movimento completo. Esses motivos básicos são transformados num notável e variado arsenal de eventos musicais através de um processo flexível de variação progressiva. As variações que os motivos

\footnotetext{
${ }^{35}$ Como demonstra o facsímile do Erste Niederschrift [primeiro manuscrito] do op.11/1, de posse do Instituto Arnold Schoenberg de Viena (apud Haimo, 1996, p. 170), não há qualquer marcação analítica na música ou em suas margens.

${ }^{36}$ Adaptação do ex. 5 do ensaio de Haimo (1996, p. 194).
} 
originais produzem carregam em si mais do que significância local, e sim, (...) criam novas ideias que, por sua vez, estão sujeitas a transformações adicionais, num processo contínuo de movimento progressivo (Haimo, 1996, p. 197)

O analista relaciona dois algoritmos principais de transformação atuando na peça: o primeiro deles, que dá origem às variantes apresentadas no ex.10, é o da expansão intervalar. ${ }^{37}$

O segundo processo destacado por Haimo é o do deslocamento de registro, cuja primeira manifestação relevante acontece na retomada da linha temática inicial, no trecho dos c. 9-11 (ex. 11).

Exemplo 11 - organização motívica na retomada do tema principal do op.11/1 (c. 9-11), segundo Haimo

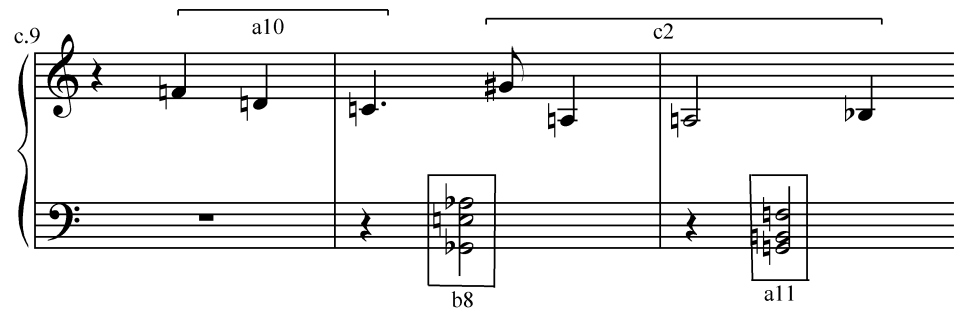

Ressaltando que "o deslocamento dramático em registro [do sol\# para o lá, no c. 10] relembra as disposições abertas dos tricordes do acompanhamento nos c. 2, 3 e 4 (a3, a4 e a5) [c.f. ex. 10]" (Haimo, 1996, p. 197), Haimo propõe, a partir disso, uma interessante conexão entre essa retomada temática e o trecho que imediatamente se Ihe segue (c. 12-13). Ou seja, a mudança de registro provocada pela variante c2 (que, por sua vez, deriva das disposições dos acordes de iniciais) abre um importante precedente (como muitas vezes, aliás, acontece na variação progressiva schoenberguiana) para os eventos presentes naquele trecho que é denominado episódio por alguns dos analistas aqui estudados (ver c. 12). ${ }^{38}$

\footnotetext{
${ }^{37}$ Haimo ressalta em seu texto que a expansão intervalar, em vários dos casos, é associada a outras transformações, como transposição e/ou inversão, por exemplo. Além disso, tratase de um processo dinâmico que, não raras vezes, retorna ao "ponto de partida" (como é o caso de a5, que retoma as três alturas originais de a, porém dispostas simultaneamente).

38 É relevante comentar que Haimo é o único dos seis analistas a perceber esse tipo de ligação derivativa entre os dois trechos, o que de fato somente se revela sob o viés da variação progressiva.
} 
É especialmente digna de menção a cadeia de nonas menores que conclui o fragmento, que pode ser relacionada a três novas variações superpostas do motivo c - c4, c5 e c6 -, através de uma combinação de inversão intervalar e deslocamento de registro. ${ }^{39}$

Exemplo 12 - transformações provocadas pela variante $c 2$ no trecho dos c. 1213, segundo Haimo

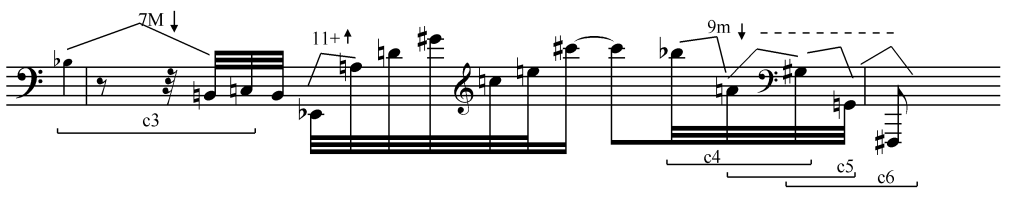

Lerdahl (2001)

A análise do op.11/1 de Lerdahl encontra-se no capítulo final de seu livro Tonal pitch space. ${ }^{40}$ Seu enfoque é inteiramente diverso dos demais analistas, voltado essencialmente para a redução prolongacional [prolongational reduction] da peça. ${ }^{41}$

Talvez uma das maiores contribuições trazidas por Tonal pitch space tenha sido a possibilidade de estender o exame de estruturas prolongacionais do universo tonal, contexto no qual foi originalmente criado, a outros tipos de organização harmônica, como o que acontece na música atonal. Para isso, Lerdahl elaborou diversas adaptações dos princípios e regras originais, buscando criar um sistema análogo ao empregado em situações correspondentes ao espaço diatônico [diatonic space]..$^{42}$

\footnotetext{
${ }^{39}$ Embora estas variantes não sejam assim numeradas por Haimo, podem ser facilmente deduzidas, a partir de seu entendimento.

${ }^{40}$ Tonal pitch space dá continuidade ao bem conhecido $A$ generative theory of tonal music (Lerdahl \& Jackendoff, 1983), aprofundando algumas de suas questões e introduzindo novos conceitos derivados ou correlatos, como pitch space [espaço das alturas], tonal tension and attraction [tensão e atração tonais], prolongational functions [funções prolongacionais], entre outros.

${ }^{41}$ De um modo geral, a redução prolongacional de uma determinada estrutura musical "associa às alturas uma hierarquia que expressa nos aspectos melódico e harmônico tensão e relaxamento, continuidade e progressão" (Lerdahl \& Jackendoff (1983, p. 8-9).

${ }^{42}$ Ver em detalhes Lerdahl (2001, p. 344-51).
} 
Segundo o autor, ao contrário da organização estratificada em cinco camadas que existe no espaço de alturas da música diatônica (ou seja, do mais ao menos importante: tônica, relação tônica-dominante, arpejo do I grau, escala diatônica e escala cromática), o espaço atonal é, por definição, desprovido de hierarquias, cabendo-lhe, portanto, a denominação de espaço plano [flat space]. Este é um fator de grande importância na adaptação de Lerdahl, pois a falta de uma hierarquia nesse tipo de espaço (que permita, entre outras coisas, a existência de inflexões melódicas, cadências etc) torna a percepção das relações de tensão e relaxamento e de progressão e continuidade em estruturas atonais consideravelmente mais tênues e intuitivamente mais frágeis do que acontece nas estruturas tonais.

No entanto, Lerdahl sustenta que, ainda assim, a abordagem prolongacional é aquela que fornece a melhor explicação para as escolhas feitas na composição de peças como o op.11/1. Em relação a este caso específico, numa crítica às abordagens analíticas de Perle, Wittlich, Forte, Ogdon e Haimo, Lerdahl pergunta:

Assumindo que uma segmentação de sets ou uma análise motívica são, ambas, viáveis, o que faz este particular conjunto ou aquele particular motivo surgir onde se encontra, naquele nível de altura [pitch leve/] específico? A resposta está na abordagem prolongacional, que posiciona as sucessões de sets ou as variações motívicas num contexto mais amplo de partida e retorno [departure and return], ${ }^{43}$ conexão linear e função" (Lerdahl, 2001, p. 372-3)

Ou seja, sem de todo questionar a validade intrínseca das outras linhas analíticas, Lerdahl argumenta que a sua própria é a única a fornecer uma perspectiva geral, funcional e reveladora da topografia tensão-distensão que atua na peça.

O principal ponto de apoio de sua tese é a sonoridade referencial [referential sonority], identificada pela sigla RS. Ela tem um papel análogo ao dos

\footnotetext{
${ }^{43}$ Referem-se a termos funcionais da teoria de Lerdahl.
} 
eventos (melódicos ou harmônicos) estruturais na música tonal, que sempre estão sujeitos às relações de continuidade (prolongação) e de progressão.

Nesse tipo de análise a segmentação em agrupamentos formais [grouping segmentation] exerce, conjuntamente com a estrutura métrica [metrical structure], um papel decisivo. ${ }^{44}$

Embora apresente diversos níveis de organização, a segmentação mais básica dos agrupamentos de Lerdahl corresponde à análise estrutural que neste estudo representa um dos parâmetros comparativos. ${ }^{45} \mathrm{O}$ ex. 13 apresenta os dois níveis que formam a estrutura básica de agrupamentos associados à análise prolongacional global da peça. ${ }^{46}$

Considerando que as ligaduras em linhas cheias representam progressões, enquanto que as tracejadas significam prolongações, é fácil perceber que as principais sonoridades de referência (RS) do op.11/1, segundo Lerdahl, são as alturas sol (na linha melódica) e o baixo sol\#, que são prolongados por quase toda a extensão da peça (reparar principalmente como isso se associa à estrutura formal). O esquema permite, além disso, perceber a condição estrutural de contraste do trecho iniciado no c. 12 , antecedendo o retorno da RS, no c. $24 .{ }^{47}$ Nota-se também, nessa análise global, a ausência do trecho dos três compassos

\footnotetext{
${ }^{44}$ A partir da interação desses dois elementos é possível elaborar uma redução temporalduracional [time-span reduction], que serve de base para a redução prolongacional. Por óbvias razões, torna-se inviável ir além dos resumidos comentários aqui apresentados. Aprofundar um assunto tão extenso e complexo, como é o caso do método das reduções e, em especial, suas várias adaptações ao idioma atonal não só exigiria um espaço considerável, como desviaria o próprio estudo de seus propósitos fundamentais. Sendo assim, passo diretamente para os resultados do analista, omitindo os detalhes do processo (para maiores informações, consultar os textos acima citados).

${ }^{45}$ Em um nível de agrupamentos mais próximo da superfície musical, o analista reconhece que o bloco principal, correspondente à seção de exposição da peça (c. 1-24), organiza-se como um longo período. Assim como Ogdon, Lerdahl considera um antecedente (c. 1-8) e um consequente com início no c. 9, com a interpolação de um contraste (episódio, para Ogdon), no c.12. No entanto, começam aí as divergências: enquanto Ogdon afirma que a continuação do consequente tem lugar no c. 18, Lerdahl a antecipa para o c. 15 , sendo o trecho dos c. 20-24 correspondente ao segmento do antecedente originalmente apresentado nos c. 4-8.

${ }^{46} \mathrm{O}$ ex. 13 transcreve a figura 8.13 de Lerdahl (2001, p. 367), omitindo a notação em "árvore" [tree notation] complementar, tendo como objetivo informar apenas o essencial para o estudo aqui desenvolvido.

${ }^{47}$ Lerdahl reconhece que o mi, do baixo do acorde final da peça é uma reminiscência do c. 12, numa interpretação semelhante a de Perle (ver o ex. 2).
} 
iniciais, considerados pelos demais analistas como essencial em suas abordagens. Embora tal trecho não seja, de modo algum, menosprezado por Lerdahl, este o analisa como uma espécie de preparação para o surgimento da sonoridade referencial do c. 5. Ou seja, este último evento é, na perspectiva global, estruturalmente mais importante do que os eventos que abrem o movimento, que possuem um caráter relativamente local. Numa tentativa de melhor ilustrar essa situação específica, o ex. 14 apresenta a análise prolongacional correspondente aos C. $1-4 .{ }^{48}$

Exemplo 13 - análise prolongacional global do op.11/1, segundo Lerdahl

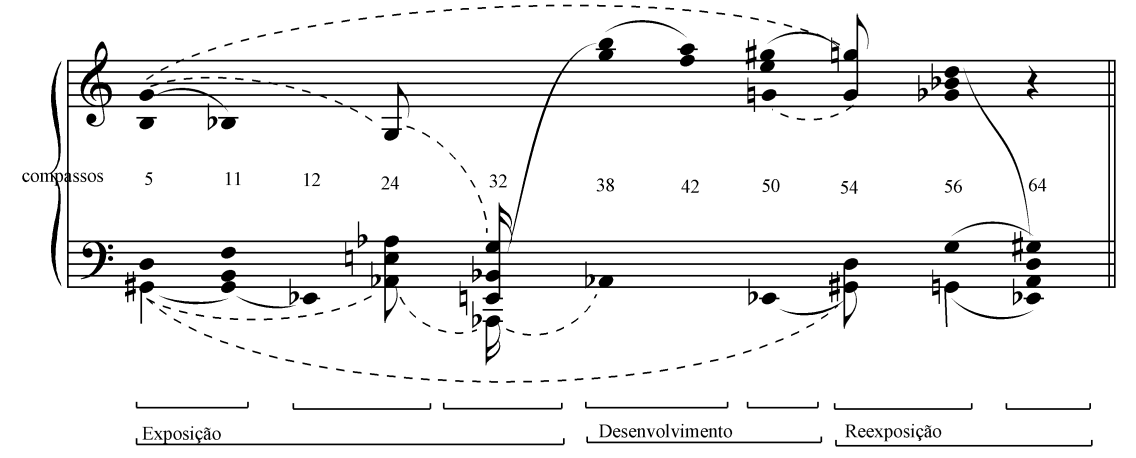

Exemplo 14 - análise prolongacional dos c. 1-3, segundo Lerdahl

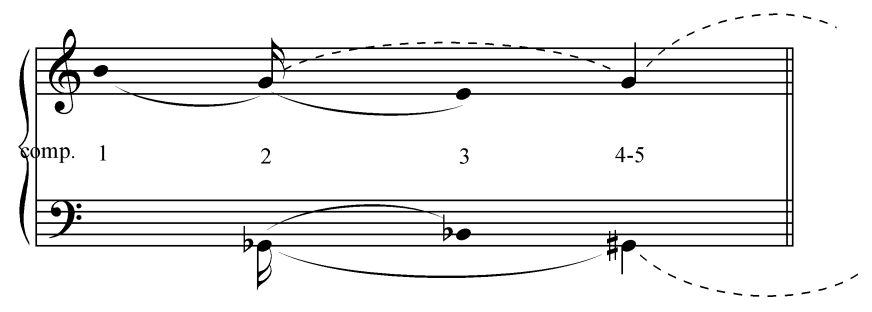

48 Transcrição resumida e parcial da figura 8-7 (Lerdahl, 2001, 359), considerando apenas o nível mais básico e apenas os eventos principais que antecedem a RS do c.5. 


\section{Conclusões}

O quadro 8 compara resumidamente as várias tendências e resultados apresentados pelos seis analistas, de acordo com os parâmetros aqui estabelecidos.

Quadro 8 - comparação entre as seis análises

\begin{tabular}{|c|c|c|c|c|c|}
\hline Parâmetros & & que & & Estrutura formal & \\
\hline Analistas & $\begin{array}{c}\text { Idioma } \\
\text { harmônico } \\
\text { considerado }\end{array}$ & $\begin{array}{l}\text { Método analítico } \\
\text { principal adotado }\end{array}$ & $\begin{array}{l}\text { forma- } \\
\text { sonata }\end{array}$ & $\begin{array}{l}\text { Identificação do } \\
\text { trecho dos c. 1-3 }\end{array}$ & $\begin{array}{l}\text { Identificação do } \\
\text { trecho iniciado no } \\
\text { c. } 12\end{array}$ \\
\hline Perle & atonal & $\begin{array}{l}\text { Teoria dos } \\
\text { Conjuntos }\end{array}$ & Sim* & Tema $a$ & $\begin{array}{l}\text { "outro elemento } \\
\text { temático" }\end{array}$ \\
\hline Wittlich & atonal & $\begin{array}{l}\text { Teoria dos } \\
\text { Conjuntos }\end{array}$ & Sim* & Início da seção I & $\begin{array}{c}\text { Contraste } \\
\text { (início da seção II) }\end{array}$ \\
\hline Forte & atonal & $\begin{array}{l}\text { Teoria dos } \\
\text { Conjuntos }\end{array}$ & Sim & $a$ & Episódio \\
\hline Ogdon & $\begin{array}{c}\text { tonal } \\
\text { expandido }\end{array}$ & $\begin{array}{c}\text { Análise } \\
\text { harmônica } \\
\text { schoenberguiana }\end{array}$ & Sim* & $\begin{array}{l}\text { Antecedente do } \\
\text { tema principal }\end{array}$ & Episódio \\
\hline Haimo & atonal* & $\begin{array}{c}\text { Análise de } \\
\text { variação } \\
\text { progressiva }\end{array}$ & - & $\begin{array}{l}\text { Primeira frase } \\
\text { do tema } \\
\text { principal }\end{array}$ & - \\
\hline Lerdahl & atonal & $\begin{array}{c}\text { Redução } \\
\text { prolongacional }\end{array}$ & Sim & $\begin{array}{l}\text { Antecedente do } \\
\text { tema principal }\end{array}$ & Contraste \\
\hline
\end{tabular}

Diversas questões se apresentam a partir da confrontação desses dados. Em primeiro lugar, parece ser adequado tecer alguns comentários em relação às análises que mostram - pelo menos em seus fundamentos metodológicos maiores afinidades entre si: as de Perle, Wittlich e Forte. Deixando de lado o aspecto formal (que parece, aliás, ser aproximadamente consensual, considerando todos os estudos comentados) e nos atendo ao exame das relações melódicoharmônicas - sem dúvida o centro de atenções nos trabalhos desses três analistas é possível perceber que, mesmo compartilhando de uma perspectiva básica focada na organização da peça em conjuntos de alturas, seus resultados, vieses particulares e procedimentos adotados são consideravelmente diferentes. Sem dúvida, o ponto nevrálgico dessa questão se apoia na problemática determinação 
da segmentação dos conjuntos: em Perle percebe-se uma preocupação em definir uma célula básica essencialmente tricordal, à qual todo o material restante se subordinaria (por derivação ou contraste), o que obliquamente poderia ser associado aos conceitos schoenberguianos de Grundgestalt [algo como "ideia primordial"] e da variação progressiva. ${ }^{49}$ É interessante constatar que tal perspectiva revela a existência de vínculos entre as essências de sua análise e a de Haimo (cujo motivo a 1 corresponde justamente à célula básica primordial de Perle). A segmentação da peça em conjuntos realizada por Perle é razoavelmente clara e lógica (ainda que um pouco superficial, se comparada às de Forte e de Wittlich), sendo orientada pelas diversas menções do tricorde básico e das demais células a ele subordinadas, em estreita correlação com os eventos temáticoformais.

Forte percebe o op.11/1 organizado em três níveis de segmentação sobrepostos - tetracordal, pentacordal e hexacordal -, revelando uma rede hierárquica extremamente intrincada, cujas fronteiras, em vários pontos da peça e neste ponto tendo a concordar com a opinião crítica de Ethan Haimo (ver nota 33) - parecem um tanto arbitrárias. Julgo que isso se deva a uma maior preocupação, por parte do analista, em comprovar a presença de certos conjuntos (em especial, hexacordes) de uso recorrente da música schoenberguiana, ${ }^{50} \mathrm{em}$ detrimento de uma busca mais consistente por coerências entre segmentos motívico-temáticos e conjuntos. Neste aspecto, Wittlich parece ter sido mais bem sucedido, pois a definição de seus hexacordes principais (empregados assumidamente como orientadores da segmentação) está mais firmemente ancorada às estruturas das ideias temáticas básicas, resultando numa análise não só mais elegante e concisa do que a de Forte (e um pouco mais aprofundada do que a de Perle), como mais sintonizada aos próprios procedimentos

\footnotetext{
${ }^{49}$ Para maiores comentários sobre esses tópicos, ver, entre outros estudos, Dahlhaus (1990, p. 128-33) e Dudeque (2005, p. 132-72).

50 Para outros estudos de Forte sobre peças de Schoenberg com abordagens semelhantes, ver, por exemplo, Forte (1972) e Forte (1978).
} 
composicionais de Schoenberg, reconhecidamente associados ao trabalho motívico. $^{51}$

Um outro aspecto importante a se destacar é a oposição existente entre essas três análises, vistas em bloco, e a de Ogdon, que considera uma estruturação tonal para a peça. ${ }^{52} \mathrm{O}$ que aparenta ser uma leitura um tanto extravagante em relação às demais, ${ }^{53}$ possui contudo uma certa base de plausibilidade, considerando o contexto no qual foi composta a obra, num período de enormes e decisivas mudanças no pensamento composicional schoenberguiano. Tal período se caracteriza por uma busca por novas formas de organização harmônica, a partir de um processo radical de expansão dos recursos da tonalidade. ${ }^{54}$ Nesses termos, é perfeitamente possível, como faz Ogdon a partir da exploração do conceito de tonalidade flutuante, considerar o op.11 como mais um passo nessa tentativa de conciliar as forças da tradição e da inovação - uma verdadeira obsessão que perpassa toda a carreira do compositor (Almada, 2010).

Com tudo isso, como seria então possível aceitar posturas analíticas tão díspares, senão antagônicas - tonal ou atonal - para uma mesma peça? A esse respeito, são interessantes alguns comentários de Thomas Christensen sobre a

51 Dahlhaus, por exemplo, sustenta que "Schoenberg nunca abandonou os modos de pensamento temático-motívico que herdou dos séculos XVIII e XIX". (Dahlhaus, 1990, p. 163).

52 É também instigante perceber que Lerdahl, com seu método analítico revolucionário derivado das concepções schenkerianas, de certa maneira também defende uma perspectiva tonal para o op.11/1, no sentido de uma estrutura referencial prolongada: neste aspecto, é interessante considerar que o principal elemento dessa sonoridade de referência - a altura sol - corresponde justamente a um dos dois centros tonais (o principal deles, aliás) estabelecidos por Ogdon.

53 Relembrando, contudo, que a interpretação de Ogdon não é um caso tão isolado como parece, haja visto a existência de várias outras análises que consideram o op. 11/1 como peça tonal, citadas por Allen Forte (ver, nota de rodapé $n^{\circ} 14$ ). Torna-se também pertinente conhecer a opinião do teórico Joseph Straus sobre este assunto específico. Em entrevista à pesquisadora Cynthia Albrecht, ele afirma que, tendo sido a obra composta em 1908, “a idéia sobre ser tonal de algum modo é perfeitamente lógica historicamente. O problema passa a ser analítico, uma vez que nem mesmo duas pessoas conseguem concordar sobre em que tonalidade a obra está." (Albrecht, 2006, p. 174).

${ }^{54}$ Ver, por exemplo, a Primeira Sinfonia de Câmara op.9 (1906), o Segundo Quarteto de Cordas op.10 (1907-8) e o ciclo de canções Das Büch der hängenden Garten op.15 (1909). Todas essas obras, em maior ou menor medida, alternam trechos tonais - alguns deles extraordinariamente expandidos - e atonais (ou, dependendo do caso, não-tonais). Para análises dessas obras sob tal perspectiva, ver Frisch (1993, p. 258-72) [para o op.10], Larson (1987) [op.15/2] e Almada (2010) [op.9]. 
"disputa" entre os artigos de Ogdon e Forte e o fato de terem sido publicados num mesmo volume, como espécies de retratos contrastantes de um mesmo objeto. Sendo ele próprio autor de uma breve porém bastante curiosa análise do op.11/1 (conectando-a ao prelúdio de Tristão e Isolda, de Wagner), afirma que

ambos os autores defendem seus casos com grande convicção e, dadas suas respectivas premissas, de forma bastante persuasiva. Se eu não subscrevo nenhum dos dois argumentos - ou, dito de maneira mais positiva, se eu me simpatizo com ambos os argumentos - não é porque eu deseje evadir-me com ajuda de uma filosofia relativista ou de um tímido pluralismo liberal; melhor do que isso, eu não percebo as análises de Forte e Ogdon como polaridades epistemológicas (Christensen, 1987, p. 38-9).

Embora não adote uma posição tão equidistante dos "extremos" (a partir de minha experiência como analista da obra schoenberguiana, percebo a peça como nitidamente atonal, ainda que julgue a interpretação de Ogdon plausível, interessante e mesmo intelectualmente estimulante), penso que as considerações de Christensen são dignas de reflexão, podendo mesmo ser expandidas e abranger as demais oposições analíticas aqui apresentadas. A despeito das defesas mais acaloradas de seus próprios trabalhos e dos comentários críticos em relação aos trabalhos alheios, não restam dúvidas sobre as virtudes de cada linha desenvolvida individualmente, que são, em seus próprios termos, bastante consistentes e, em muitos aspectos, mutuamente complementares, ainda que persistam, evidentemente, áreas conflitantes. Além disso, como pretendi demonstrar nestes comentários conclusivos, o quadro se mostra com menos arestas do que aparenta, considerando também os vários pontos de contato que existem entre os estudos, ainda que alguns deles se revelem apenas de maneira sutil, como é o caso, por exemplo, das afinidades entre as análises de Perle e Haimo ou as de Ogdon e Lerdahl.

\section{Referências}

ALBRECHT, Cynthia Macedo. Uma conversa com Joseph Straus. Opus, Goiânia, vol. 12, no. 1, p. 169-79, 2006. 
ALMADA, Carlos de L. "Nas fronteiras da tonalidade": Tradição e inovação na harmonia da Primeira Sinfonia de Câmara, op.9, de Arnold Schoenberg. 2010. Tese (Doutorado em Música) - Centro de Letras e Artes, Universidade Federal do Estado do Rio de Janeiro.

CHRISTENSEN, Thomas. Schoenberg's op.11, no. 1: A parody of pitch cells from Tristan. Journal of the Arnold Schoenberg Institute, Los Angeles, vol. X, no. 1, p. 38-43, 1987.

DAHLHAUS, Carl. Schoenberg and the New Music (Derrik Puffett \& Alfred Clayton, trad.). Cambridge: Cambridge University Press, 1990.

DUDEQUE, Norton. Harmonia tonal e o conceito de monotonalidade nos escritos de Arnold Schoenberg (1874-1951). Dissertação (Mestrado em Musicologia) Escola de Comunicações e Artes, Universidade de São Paulo, 1997.

. Music theory and analysis in the writings of Arnold Schoenberg (1874-1951). Aldershot: Ashgate Publishings, 2005.

FORTE, Allen. Sets e nonsets in Schoenberg's atonal music. Perspectives of New Music, vol. 11, no.1, p.43-64, 1972.

Press, 1973.

. The structure of atonal music. New Haven: Yale University

Schoenberg's creative evolution: The path to atonality. The Musical Quaterly, vol. LXIV, no.2, p.133-75, 1978.

The magical kaleidoscope: Schoenberg's first atonal masterwork, op.11, number 1. Journal of the Arnold Schoenberg Institute, vol. V, no. 2, p. 127-68, 1981.

FRISCH, Walter. The early works of Arnold Schoenberg (1893-1908). Los Angeles: University of California Press, 1993.

HAIMO, Ethan. Atonality, analysis and the Intencional Fallacy. Music Theory Spectrum, vol. 18, no. 2, p. 167-199, 1996.

HERSCHKOWITZ, Fillip. La fonti tonali della dodecafonia di Schoenberg. Nuova rivista musicale italiana, ano VIII, nº4, 10/12, p. 540-578, 1974.

LARSON, Steve. A tonal model of an "atonal" piece: Schoenberg's Op. 15. number 2. Perspectives of New Music, vol. 25, n 1/2, p. 418-433, 1987.

LERDAHL, Fred \& JACKENDOFF, Ray. A generative theory of tonal music. Cambridge: The MIT Press, 1983.

LERDAHL, Fred. Tonal pitch space. Nova York: Oxford University Press. 2001.

OGDON, Will. How tonality functions in Schoenberg's opus $11, \mathrm{n}^{\circ} 1$. Journal of the Arnold Schoenberg Institute, vol. V, no. 2, p. 169-82, 1981.

PERLE, George. Serial composition and atonality: an introduction to the music of Schoenberg, Berg and Webern. Londres: Faber \& Faber, 1962. 
SCHOENBERG, Arnold. Fundamentals of musical composition. (Gerald Strang, ed.) Londres: Faber \& Faber, 1990.

2001. . Harmonia. (Marden Maluf, trad.). São Paulo: Editora Unesp, Funções estruturais da harmonia. (Eduardo Seincman, trad.) São Paulo: Via Lettera, 2004.

STRAUS, Joseph. Introduction to post-tonal theory. Englewood Cliffs: PrenticeHall, 1990.

WITTLICH, Gary. Interval set structure in Schoenberg's op. 11, $\mathrm{n}^{\circ} 1$. Perspectives of New Music, vol. 13, no. 1, p. 41-55, 1974. 